\title{
Activities and molecular characterization of petroleum hydrocarbons degrading rhizobacteria from mangrove plants (Rhizophora sp.) in Kulon Progo, Yogyakarta, Indonesia
}

\author{
VIVEKANANDA VINSENSIUS BENGET ${ }^{1}$, ENDAH RETNANINGRUM ${ }^{2, \bullet}$ \\ ${ }^{1}$ Graduated Program in Biology, Faculty of Biology, Universitas Gadjah Mada. Jl. Teknika Selatan, Sekip Utara, Sleman 55281, Yogyakarta, Indonesia \\ ${ }^{2}$ Microbiology Laboratory, Faculty of Biology, Universitas Gadjah Mada. Jl. Teknika Selatan, Sekip Utara, Sleman 55281, Yogyakarta, Indonesia. \\ Tel./fax.: +62-274-580839, \email: endahr@ugm.ac.id, nandatampubolon44@gmail.com
}

Manuscript received: 26 May 2019. Revision accepted: 2 December 2019.

\begin{abstract}
Benget VV, Retnaningrum E. 2020. Activities and molecular characterization of petroleum hydrocarbons degrading rhizobacteria from mangrove plants (Rhizophora sp.) in Kulon Progo, Yogyakarta, Indonesia. Biodiversitas 21: 21-27. The increasing number of human population density around mangrove ecosystems has resulted in its pollution, particularly oil spills. Rhizobacteria have metabolic abilities that make them possible to live in polluted environmental conditions and the potential to be biological agents for oil remediation. However, investigations of rhizobacteria especially from rhizospheres of mangrove plants (Rhizophora sp.) and their potential use in remediation remains limited. Therefore, the purposes of this research were to investigate the ability of selected isolate in the degradation of petroleum hydrocarbons and identify its isolate using $16 \mathrm{~S}$ rRNA gene. Observation of that degradation ability was conducted by inoculating the isolate in Bushnell-Haas Minimal Salt (BHMS) medium containing crude petroleum $0.01 \%$. After 10 days of incubation, the degradation hydrocarbons were analyzed by measuring Total Petroleum Hydrocarbons (TPH) using Gas Chromatography-Flame Ionization Detector (GC-FID) method. Four rhizobacteria isolate from rhizospheres of mangrove plants (Rhizophora sp), NMKP1, NMKP2, NMKP3, and NMKP4 were analyzed based on their growth in Bushnell-Haas Minimal Salt (BHMS) medium containing crude petroleum $0.01 \%$. The results revealed that NMKP4 isolate had the highest specific growth rate. In addition, it could degrade those hydrocarbons pollutants as much of $98.72 \%$ within 10 days. Based on molecular characterization showed that NMKP4 isolate was in the same cluster as Pseudomonas sp. CO03.
\end{abstract}

Keywords: 16S rRNA, GC-FID, mangroves, oil spills, Pseudomonas, Rhizophora

\section{INTRODUCTION}

Petroleum is an important energy source because petroleum has a significant percentage in meeting world energy consumption. Indonesia is one of oil-producing countries in the world. BP Statistical Review of World Energy (2018) data shows Indonesia produces 949,000 barrels of oil per day. Most petroleum hydrocarbon compounds are known to be carcinogenic, mutagenic, and classified as major environmental pollutants by US Environmental Protection Agency. Content of these contaminants has a long-term effect on ecosystem and increases presence of toxicity in organisms to the top of food chain (Khan et al. 2018). Biodegradation of hydrocarbon-contaminated soils, using microorganisms that have potential to degrade or detoxify these contaminants, has been proven as an environmentally friendly and low-cost method. Oil-degrading microorganisms have an enzyme system and metabolic abilities, allowing them to resist polluted environmental conditions (Meng et al. 2018; Ji et al. 2019).

Mangroves are intertidal wetland swamps that lie along the coastline of tropical and subtropical regions that have large ecological and economic interests. However, throughout world mangroves are the most threatened environment of damage. In addition, mangrove forest has decreased its quality due to oil pollution, especially during their petroleum exploration (Chai et al. 2019; Garcia et al. 2019). Extent to impact of environmental damage is still unknown but may be a major problem in the future. A method to restore these environmental conditions is very important to be developed to prevent damage mangrove ecosystems.

Mangrove forest area in Kulon Progo, Yogyakarta, Indonesia is also inseparable from threat of damage. In general, most of the mangrove area's environment is located in areas with high anthropogenic influence and therefore mangrove environment is also inseparable from exposure to pollutants, such as exposure to oil spills. The oil pollutants found in mangrove area come from the activities of shrimp farms that are also located in the area. The oil pollutant comes from the use of a diesel engine that functions as an aerator for ponds. In addition, oil pollutants also come from motorized boats owned by residents along river estuary in the mangrove area. Oil pollutants are sourced from refueling activities of motorboat.

Rhizosphere is an ideal area for growth of soil microorganisms that are generally dominated by bacteria, actinomycetes and fungi (Renu et al. 2019). This area is also rich exudates that are produced by plants through the process of root secretion. These exudates are then decomposed by microorganisms that produce energy and 
precursor compounds. Then, these precursor compounds can be utilized by themselves and plants (Haichar et al. 2014; Sasse et al. 2018). Hence, the rhizosphere microorganisms play a role in the nutrient cycle and also in the process of soil formation. Therefore, plant growth greatly affects the activity of microorganisms, as well as controlling biodiversity of root pathogens (Clairmont et al. 2019; Wei et al. 2019). In addition, the rhizobacteria were also reported to be able to degrade of that hydrocarbon pollutants in the soil environment (Retnaningrum and Wilopo 2018). Based on those reasons, this study aims to obtain the best rhizobacteria species from mangrove plants (Rhizophora. sp) at Kulon Progo, Yogyakarta which has ability to degrade petroleum hydrocarbons and to identify it by $16 \mathrm{~S}$ rRNA gene.

\section{MATERIALS AND METHODS}

\section{Location and sample collection}

Soil samples were collected from the rhizosphere of mangrove plants (Rhizophora sp) located at Wanatirta Mangrove Forest, Kulon Progo, Yogyakarta. Rhizospheric soil samples were taken at one point randomly where there was exposed to oil pollutants which characterized by the presence of oil shine above the water surface where the mangrove plants grew. A $5 \mathrm{~g}$ of rhizospheric soil samples were taken at the root part, then filtered using a sieve with $2 \mathrm{~mm}$ diameter sieve hole (Rajaei et al. 2013). The soil samples obtained were then stored at $-20^{\circ} \mathrm{C}$.

\section{Analysis of rhizospheric soil samples}

Soil samples were analyzed based on $\mathrm{pH}$ values and Total Petroleum Hydrocarbon (TPH). Measurements of $\mathrm{pH}$ values were conducted using a $\mathrm{pH}$ meter. Previously $\mathrm{pH}$ meter was calibrated using a buffer solution $\mathrm{pH} 4.0$ and 7.0, then washed with distilled water and dried with tissue. The $\mathrm{pH}$ values of the samples were then measured 3 times to obtain the representative data. For measuring TPH, soil sample previously was homogenized and was then taken as much as $5 \mathrm{~g}$ and put into a large test tube. The soil sample was then extracted with $10 \mathrm{ml}$ of n-hexane and allowed to stand until the solution separates completely. The top layer was then taken and injected as much as $1 \mu \mathrm{L}$ in Shimadzu GC-2010 which was equipped with a Flame Ionization Detector (FID), using a RTX-5 column, $30 \mathrm{~m}$ long (Srivastva et al. 2017). The standard and extractant were also injected under the same conditions as much as $1 \mu \mathrm{L}$ in Shimadzu GC-FID. The TPH levels were then calculated using the following formula (Mishra et al. 2001):

$$
T P H(\%)=\frac{\text { Sample area }- \text { extractant area }}{\text { Std. area }- \text { extractant area }} X \text { DF X Std.conc. }(1000 \mathrm{mg} / \mathrm{L})
$$

Where:

DF was dilution factor

\section{Isolation and phenotypic characterization of rhizobacteria from Rhizophora sp.}

The petroleum hydrocarbons degrading rhizobacteria from Rhizophora sp were isolated from the rhizospheric soil samples by inoculating them into Bushnell-Haas Minimal Salt Broth Medium (BHMS) with addition of $0.01 \%$ crude oil. The culture was then incubated at room temperature, on a rotary shaker $(180 \mathrm{rpm})$ for 7 days. The culture was then subcultured two times into fresh medium of BHMS with addition $0.01 \%$ crude oil. The adaptive rhizobacteria cultures were then purified into BHMS agar using pour plate method. Purified rhizobacteria isolates were characterized phenotypically by analyzing their cell shape, gram staining and colony properties (color, shape, elevation, margin and inner structure).

Gram staining method was carried out to identify the rhizobacteria cells based on their different cell wall constituents using 2 kinds of stain. Firstly, a small amount of isolate culture was spread on the surface of the slide. The smear was then fixed physically by heat to the surface of the slide. As much as 2-3 drops of crystal violet were dropped on a surface of slide sample for 60 seconds. The slide sample was then washed using water and dried. A total of 2-3 drops of Lugol solution was dropped over the slide sample for 60 seconds. Slide sample was washed with water and dried. Slide sample was further dropped 2-3 drops of an alcohol-acetone solution for 30 seconds, then washed again and dried. Furthermore, the slide sample was dripped with a safranin solution of 2-3 drops for 60 seconds, then washed and dried. Finally, the slide sample was then observed under a light microscope.

\section{The growth of rhizobacteria isolates from Rhizophora} sp.

The growth of rhizobacteria isolated from Rhizophora sp. was measured by their specific growth rate by culturing them into BHMS medium with addition of crude oil 0.01 $\%$. Each rhizobacteria isolate was inoculated into $250 \mathrm{ml}$ liquid BHMS medium with addition of crude oil $0.01 \%$. The specific growth rates of isolates can be measured by analyzing their growth at an interval time of 12 hours for 72 hours using total plate count (TPC). Finally, the specific growth rate can be calculated using the equation reported by Maier and Pepper (2009).

$$
\mu=0.693 \times \frac{\log N t-\log N 0}{0.301 \times t}
$$

Where:

$\mathrm{k}$ : The constant of growth rate (generation/time)

N0: The initial number of bacteria during the exponential phase $(\mathrm{CFU} / \mathrm{mL})$

$\mathrm{N}$ : The number of bacteria after growing during t-time (CFU/mL)

$\mathrm{t}$ : The growth time at exponential phase (seconds) 


\section{Activity of rhizobacteria isolates on petroleum hydrocarbons degrading}

Selected rhizobacteria isolate was cultured in BHMS medium with addition of $0.01 \%$ crude oil and incubated on a rotary shaker at a speed of $180 \mathrm{rpm}$ at room temperature. After 10 days of incubation, the $\mathrm{pH}$ value and TPH of culture were analyzed. For analysing the TPH of culture, firstly it was extracted using $40 \mathrm{ml}$ dichloromethane in separating funnel. Solution mixture was then stirred for 3 minutes with a rest period of 10 minutes. Extracted sample was then reacted with $10 \mathrm{mg} \mathrm{Na}_{2} \mathrm{SO}_{4}$ in a glass funnel coated with glass wool. Finally, the sample was collected into a flask and washed using dichloromethane. The top layer then was taken and injected as much as $1 \mu \mathrm{L}$ into GCFID. Preparation and measurement of standard, extractant and extracted samples were carried out in the same procedure as in the previous TPH analysis.

\section{Molecular identification of rhizobacteria isolated from Rhizophora sp}

The overnight of the rhizobacteria culture in the Nutrient Broth (NB) medium was prepared for extracting DNA using the Quick-DNA ${ }^{\mathrm{TM}}$ Fungal/Bacterial Miniprep (Zymo Research). The extract of DNA was then suspended in $500 \mu \mathrm{L}$ of buffer TE. The purity of DNA extracted was measured at A260/280 wavelengths using UV-Vis Nanodrop-Spectrophotometer (Thermo Scientific) with three replication.

The DNA further used as DNA template in PCR reactions. The $16 \mathrm{~S}$ rRNA gene was amplified by using the primer pairs 27F / 1429R (27F: 5'-AGA GTT TGA TCC TGG CTC AG-3', 1429R: 5'-TAC GGY TAC CTT GTT ACG AGA CTT -3'). Amplification was carried in several cycles of reaction including predenaturation at $95^{\circ} \mathrm{C}$ for 3 minutes, amplification of 30 cycles included denaturation at $95^{\circ} \mathrm{C}$ for 30 seconds, annealing at $57^{\circ} \mathrm{C}$ for 1 minute, extension at $72^{\circ} \mathrm{C}$ for 1 minute 40 seconds and cooling at $4^{\circ} \mathrm{C}$.

The PCR product samples were detected qualitatively using electrophoresis with $1 \%$ of agarose (w/v) and visualized using UV Transluminator. This PCR product was then sequenced by Sanger method. Sequencing results were compared with database on NCBI website (National Center for Biotechnology) through the BLAST tools (www.ncbi.nlm.nih.gov). Furthermore, phylogenetic tree was constructed using Neighbor-Joining (NJ) method with MEGA 7 program.

\section{Data analysis}

The experimental data were statistically analyzed with SPSS version 12. The means of tested parameters were analyzed by Duncan's Multiple Range Test (DMRT) and ANOVA $(\mathrm{p}<0.05)$

\section{RESULTS AND DISCUSSION}

\section{Rhizosphere soil samples from Rhizophora sp.}

Rhizosphere soil samples were taken at one point randomly from mangroves area in Kulon Progo, Yogyakarta, Indonesia where there was exposure to oil pollutants which characterized by the presence of oil glints above the surface of water where the plants grew. From the measurements, it showed that the $\mathrm{pH}$ and $\mathrm{TPH}$ values of samples were 7.26 and $109.87 \mathrm{mg} / \mathrm{mL} \quad(0.01 \%)$, respectively. These results could describe that the mangrove area was contaminated hydrocarbon. However, Rhizophora sp. could grow well which might be correlated with the presence and activities of rhizobacteria population in the mangrove ecosystem. The $\mathrm{pH}$ values of sample tend alkaline, this indicated the presence of mineral salt content in the area (Ceccon et al. 2019). These measurement results were also important for preparing medium for isolating and culturing rhizobacteria isolates.

\section{Phenotypic characters of rhizobacteria isolated from \\ Rhizophora sp.}

Four isolates of petroleum hydrocarbons degrading rhizobacteria were obtained, each coded NMKP1, NMKP2, NMKP3, and NMKP4. These isolates were able to use crude oil for their $\mathrm{C}$ source. The observation results of phenotypic characters isolates were displayed in Table 1. The cell morphology of NMKP1 and NMKP3 isolates were rod-shaped, whereas NMKP2 and NMKP4 isolates had short rod-shaped. Based on the Gram staining results, all rhizobacteria isolates showed Gram-negative. In addition, all isolates showed the same white color, irregular shape, effuse elevation and smooth inner structure of their colonies. These results matching with the profile of Pseudomonas sp which explained in Bergey's Manual Systematic of Bacteriology (Brenner et al. 2005).

Table 1. Morphological characters of rhizobacteria isolated from Rhizophora sp.

\begin{tabular}{llllll}
\hline \multirow{2}{*}{ Characters } & & \multicolumn{3}{c}{ Isolate } \\
\cline { 3 - 5 } & & \multicolumn{1}{c}{ NMKP1 } & NMKP2 & NMKP3 & NMKP4 \\
\hline Cell morphology & Shape & Rod-shaped & Short rod-shaped & Rod-shaped & Short rod-shaped \\
& Gram stain & Negative $(-)$ & Negative $(-)$ & Negative $(-)$ & Negative $(-)$ \\
Colony morphology & Color & White & White & White & White \\
& Shape & Irregular & irregular & Irregular & Irregular \\
& Elevation & Effuse & effuse & Effuse & Effuse \\
& Inner structure & Smooth & Smooth & Smooth & Smooth \\
\hline
\end{tabular}


The growth of rhizobacteria isolates from Rhizophora sp.

The number of rhizobacteria cells varied with time incubation and the kind of isolate (Figure 1). The number of NMKP1, NMKP2, NMKP3 and NMKP4 isolates at 12 hours growth were $2.18 \times 10^{7}, 1.525 \times 10^{7}, 1.86 .5 \times 10^{7}$ and $0.505 \times 10^{7} \mathrm{CFU} / \mathrm{mL}$. During $12-24$ hours incubation, all isolates showed flat growth curves. These were probably because each isolate synthesized an enzyme to degrade hydrocarbons which occurred in a lag phase. In addition, in these phase cells were also synthesized enzymes needed by their cells for metabolic processes. All isolates entered the exponential phase and reach its peak in different time incubation and cells number. The highest number cells of NMKP1, NMK3, and NMK4 isolates were $2.345 \times 10^{7}$, $3.065 \times 10^{7}$ and $3.15 \times 10^{7} \mathrm{CFU} / \mathrm{mL}$, respectively which were reach at 48 hours incubation. Whereas, NMKP2 isolate was reached the highest cells number of $2.105 \times 10^{7} \mathrm{CFU} / \mathrm{mL}$ at 36 hours incubation. During these peak curves, the rhizobacteria divided rapidly and increased logarithmic according to time. (Madigan et al. 2012).

Those growth observations could be further calculated to obtain their growth kinetics, as shown in Table 2 . The highest specific growth rate $(\mu)$ of NMPK4 isolate revealed that isolate could grow and adapt quickly in the crude oil exposure. Furthermore, this isolate was selected and measured its activity in BHMS medium with $0.01 \%$ crude oil addition.

\section{The activity of rhizobacteria isolates on petroleum hydrocarbons degrading}

The activity of selected rhizobacteria isolates (NMPK4) on petroleum hydrocarbons degrading was determined by culturing its isolate in medium BHMS containing $0.01 \%$ crude oil at 10 days incubation. During time of incubation, isolate had an ability to use hydrocarbon compounds as carbon sources. This ability could be seen from the changes in hydrocarbon compounds concentration. Total Petroleum Hydrocarbon (TPH) is a method to determine the value of petroleum hydrocarbons content in liquid media which can be measured using Gas Chromatography. The results showed that the TPH of culture after 10 hours incubation was $0.00014 \%(\mathrm{p}<0.05)$ which shown in Table 3 . There was a decrease which equals $98.72 \%$ in TPH levels after 10 days of incubation. These results indicate that NMKP4 isolate could degrade petroleum hydrocarbons well. These results were in accordance with a previous researcher who reported that rhizobacteria isolate from mangrove plants at
Rio de Janeiro, Brazil was able to reduce TPH values by up to $97 \%$ (Carmo et al. 2011) Therefore, it could be said that rhizosphere of mangrove plants have a great potential for obtaining novelty bacterial isolates which have an ability to degrade petroleum hydrocarbons.

The measurements of $\mathrm{pH}$ cultures showed that it was decreased significantly $(\mathrm{p}<0.05)$. This decreasing in $\mathrm{pH}$ culture was caused by rhizobacteria activity which uses and degrades hydrocarbons for its metabolism. During hydrocarbons degradation process, their compounds will be degraded by bacteria into alcohol using monooxygenase which converts hydrocarbons to alcohol. Then the alcohol will be converted into aldehyde which will be converted to acid. The acid will enter $B$-oxidation pathway. Therefore, the acid produced from this metabolic process affects $\mathrm{pH}$ in culture media (Al-Hawash et al. 2018).

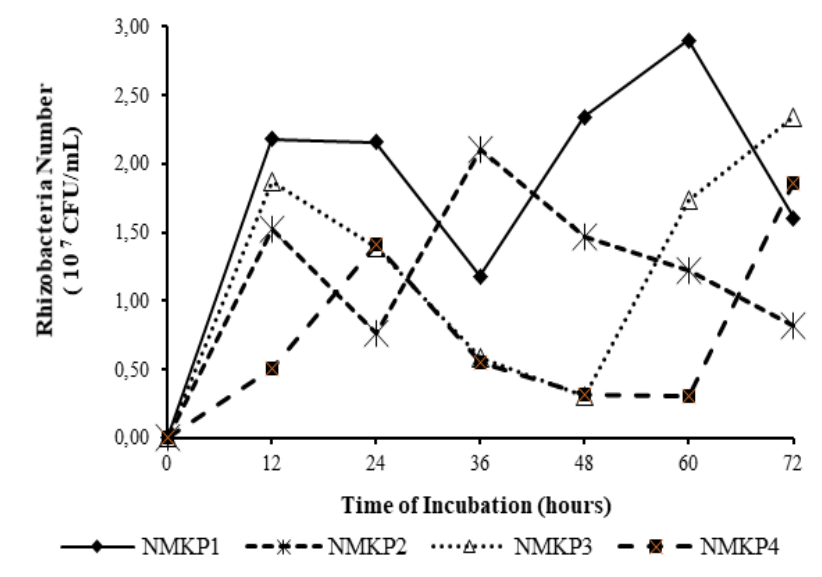

Figure 1. The growth of rhizobacteria isolates from Rhizophora sp in BHMS medium with $0.01 \%$ crude oil addition during 72 hours incubation

Table 3. The change of TPH and $\mathrm{pH}$ of NMPK4 culture after 10 days incubation

\begin{tabular}{lcc}
\hline \multicolumn{1}{c}{ Measurements } & \multicolumn{2}{c}{ Time Incubation } \\
& \multicolumn{2}{c}{ (days) } \\
& $\mathbf{0}$ & $\mathbf{1 0}$ \\
\hline Total Petroleum Hydrocarbon (TPH) (\%) & 0.01 & 0.00014 \\
$\mathrm{pH}$ & 7.53 & 7.51 \\
\hline
\end{tabular}

Table 2. Growth kinetics of rhizobacteria isolates from mangrove plants (Rhizophora sp.)

\begin{tabular}{lcccc}
\hline Rhizobacteria isolate & $\begin{array}{c}\text { No } \\
(\text { CFU/mL) }\end{array}$ & $\begin{array}{c}\text { N } \\
\text { (CFU/mL) }\end{array}$ & $\begin{array}{c}\text { K } \\
\text { (Generation/second) }\end{array}$ & \multicolumn{1}{c}{} \\
\hline NMKP1 & $2.180 \times 10^{6}$ & $2.900 \times 10^{7}$ & 0.0086 & 0.005 \\
NMKP2 & $1.525 \times 10^{5}$ & $2.105 \times 10^{5}$ & 0.0194 & 0.010 \\
NMKP3 & $1.865 \times 10^{5}$ & $3.065 \times 10^{5}$ & 0.0199 & 0.010 \\
NMKP4 & $5.050 \times 10^{4}$ & $3.150 \times 10^{6}$ & 0.0734 & 0.050 \\
\hline
\end{tabular}

Note: $\mathrm{K}$ was the constant of growth rate, N0: the initial number of rhizobacteria during the exponential phase, N: the number of rhizobacteria after growing during $\mathrm{t}$-time, $\mathrm{t}$ : the growth time at exponential phase and $\mu$ : the specific growth rate. 
Table 4. Results of measurement purity sample DNA isolates NMKP4

\begin{tabular}{lc}
\hline \multicolumn{1}{c}{ Parameters } & Result \\
\hline Concenntration $(\mathrm{ng} / \mu \mathrm{L})$ & $307.50 \pm 1.500$ \\
DNA purity value $(\mathrm{A} 260 / 280)$ & $1.91 \pm 0.002$ \\
Volume $(\mu \mathrm{L})$ & $30.00 \pm 0.060$ \\
\hline
\end{tabular}

\section{Molecular identification of NMKP4 isolate with 16S rRNA gene}

Molecular identification was carried out using ribosomal gene as a molecular marker to confirm the identity of the selected strain. Previously, rhizobacterial DNA was extracted and checked it purity and concentration using UV-Vis Nanodrop-Spectrophotometer spectrophotometer (Sambrook et al. 1989). The results showed that DNA extract of NMKP4 isolate had a ratio 1.91 (Table). This ratio value was still in the range of 1.8 to 2.0 included in the pure category. If the ratio $<1.8$ indicated it DNA extract was contaminated by phenol and solvent. Whereas, if ratio > 2.0 indicated it DNA extract was contaminated by proteins and other compounds, such as RNA.

The DNA extract of NMKP4 isolate was then used as templates for amplification PCR using primers 27F (5'AGA GTT TGA TCC TGG CTC AG-3') and 1429R (5'TAC GGY TAC CTT GTT ACG AGA CTT -3'). These pair of primer $27 \mathrm{~F} / 1429 \mathrm{R}$ could amplify almost all of $16 \mathrm{~S}$ rRNA genes (Osborne et al. 2006). The PCR products then visualized using electrophoresis which displayed in Figure 2. The amplified product showed a single band approximately $1500 \mathrm{bp}$, corresponding to the expected size of the 16S rRNA genes (Janda and Abbott 2007). This PCR product was finally sequenced with both of $27 \mathrm{~F}$ and $1429 \mathrm{R}$ primers. Some systems could determine nucleotide sequences through reading one primer, but reading with two primers gives more accurate results.

The sequencing results were then compared to reference sequences which could compare their identity values, between the sequence of sample isolates (Query) and reference sequence (Sbjct) throughout sequence examined
(Table 5). The results revealed that NMKP4 isolate had a similarity of $99.14 \%$ with Pseudomonas sp. CO03. As explained by Miller et al. (1990) identities were presentations of compatibility between sequences queries (sequences that are owned) with database nucleotide sequences. According to Dighe et al. (2004) and Greenwood et al. (2012) if the similarity of 16S rRNA coding genes base sequence more than $97 \%$ could be considered the same species. Therefore, this NMKP4 isolate was identified as Pseudomonas sp. This molecular identification result of NMKP4 isolate was congruence with previous phenotypic characterization.

The sequence data of 16S rRNA gene could describe the degree of similarity between two taxa. Therefore, it could be used to construct phylogenetic trees that showed the relationship among ancestors and kinship of organisms (Godini and Fallahi 2019). This 16S rRNA gene was already used widely for constructing phylogenetic trees. In addition, those 16S rRNA genes were found in all prokaryotes. This 16S rRNA gene also had variable and conserve areas that reflected phylogenetic relationships among species (Van de Peer 2009; Mitreva 2017).

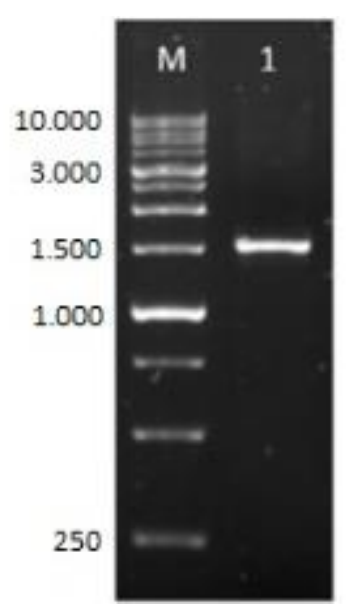

Figure 2. Results of NMKP4 isolate DNA amplification with $27 \mathrm{~F}$ and 1429R primers. (M: Marker, 1: NMKP4 isolate)

Table 5. BLAST results of 16S rRNA gene sequence NMKP4 isolate

\begin{tabular}{lrlll}
\hline Homologous species & Identities & $\begin{array}{l}\text { Accession } \\
\text { Number }\end{array}$ & Source of isolates & References \\
\hline Pseudomonas sp. CO03 & $99.14 \%$ & HQ670705.1 & Tobacco rhizosphere & Demaneche et al. (2011) \\
Pseudomonas sp. M1 & $99.07 \%$ & DQ026293.1 & River sediments & Santos et al. (2007) \\
Pseudomonas sp. strain ADP & $99.07 \%$ & AM088478.1 & Garden soil & Lang et al. (2007) \\
Uncultured Pseudomonas sp. clone HN Pc5 & $99.00 \%$ & KX363680.1 & Sandflies & Li et al. (2016) \\
Pseudomonas sp. NBIWW4 & $98.93 \%$ & KF765796.1 & Activated sludge & Tan et al. (2015) \\
Pseudomonas sp. NBUS7 & $98.93 \%$ & KF765793.1 & Activated sludge & Tan et al. (2015) \\
Pseudomonas sp. G4 & $98.86 \%$ & AB222019.1 & Crude petroleum-contaminated soil & Ozaki et al. (2006) \\
Uncultured Pseudomonas sp. clone HN Pc2 & $98.79 \%$ & KX363681.1 & Sandflies & Li et al. (2016) \\
Pseudomonas citronellolis strain ADC-33 & $98.64 \%$ & KM210233.1 & Activated sludge & Ntougias et al. (2014) \\
Pseudomonas sp. I-P & $98.50 \%$ & KC853422.1 & Wastewater treatment plant & Xu et al. (2013) \\
\hline
\end{tabular}




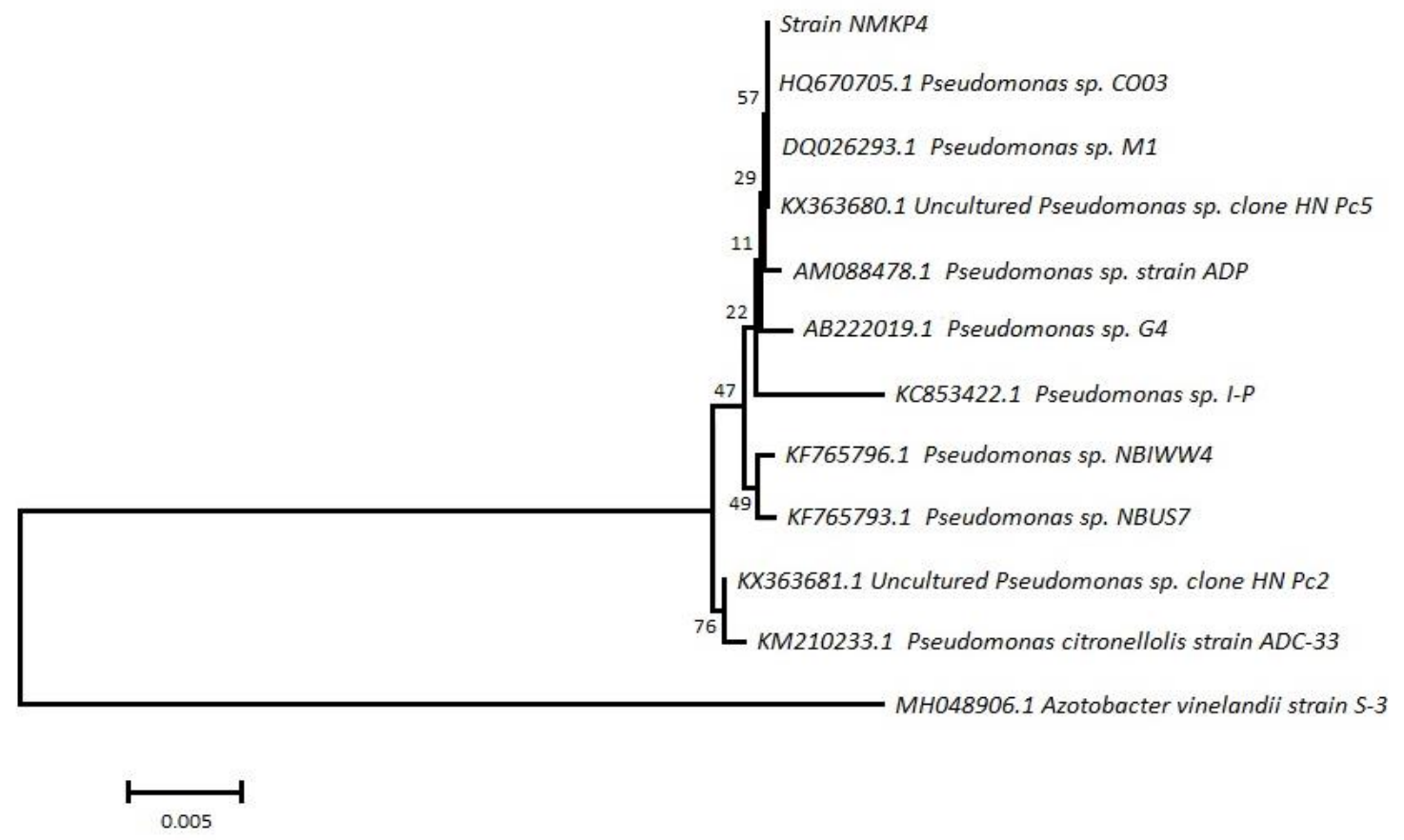

Figure 3. The results of phylogeny tree construction NMKP4 isolate

For constructing phylogeny tree, this analysis was carried out using Maximum Likelihood method due to several reasons explained by previously researchers. This method reconstructed of phylogenetic tree based on DNA sequences which include automorphic, plesiomorphic, and synapomorphic characters (Van de Peer 2009). In addition, Heng (2006) and Heath et al. (2006) stated that Maximum Likelihood could apply sequence evolution models which were ideal for building phylogeny tree using sequences data.

In most phylogeny tree structuring incorporated outgroups into analysis. This outgroup was outside of group tested but still had a relationship with the test group. In this analysis, Azotobacter vinelandii strain S-3 was chosen as outgroup. This selection was choose based on the fact that the test group (Pseudomonas sp) and outgroup (Azotobacter vinelandii strain S-3) was classified in the same Family of Pseudomonadaceae.

The result of phylogeny tree construction as displayed in Figure 3, it revealed that NMKP4 isolate was in the same cluster as Pseudomonas sp. CO03. This was consistent with the results of analysis using BLAST algorithm which showed NMKP4 isolate had a similarity of $99.14 \%$ to partial sequence of Pseudomonas sp. CO03. These result of the similarities was greatest compared to other comparative isolates. Thus it could be concluded that petroleum hydrocarbons degrading rhizobacteria from mangrove plants (Rhizophora sp.) in Kulon Progo, were identified as Pseudomonas sp. Previous study conducted by Carmo et al. (2011) also reported that one of hydrocarbons degrading rhizobacteria isolates from mangrove in Rio de Janeiro was identity with Pseudomonas sp. Whereas, other isolates were identities with Azospirillum sp., Acinetobacter sp.,
Paenibacillus sp., and Ralstonia sp. Therefore, based on these investigations, it could be concluded that NMKP4 isolates from rhizospheres of mangrove plants in Kulon Progo had the best ability to grow in BHMS medium containing petroleum hydrocarbons $0.01 \%$ and ability to degrade those pollutants as much as $98.72 \%$ for 10 days. This isolate clearly characterized molecularly based on $16 \mathrm{~S}$ rRNA gene was same cluster as Pseudomonas sp CO03.

\section{REFERENCES}

Al-Hawash AB, Dragh MA, Li S, Alhujaily A, Abbood HA, Zhang X, Ma F. 2018. Principles of microbial degradation of petroleum hydrocarbons in the environment. Egypt J Aquat Res 44: 71-76.

BP Statistical Review of World Energy. 2018. Full report-Statistical Review of World Energy. Pureprint Group Limited, UK ISO 14001, FSC $®$ certified and CarbonNeutral $®$.

Brenner DJ, Krieg NR, Staley JR. 2005. Bergey's Manual Systematic Bacteriology. Springer, New York (US).

Carmo FL, Santos HF, Martins EF, Elsas JD, Rosado AS, Peixoto RS 2011. Bacterial structure and characterization of plant growth promoting and oil degrading bacteria from the rhizosphere of mangrove plants. J Microbiol 49 (4): 535-543.

Ceccon DM, Helisson Faoro, Lana PD, Emanuel, de Souza M, Pedrosa FDO. 2019. Metataxonomic and metagenomic analysis of mangrove microbiomes reveal community patterns driven by salinity and $\mathrm{pH}$ gradients in Paranaguá Bay, Brazil. Sci Total Environ 694 (1): 133609.

Chai M, Ding H, Shen X, Li R. 2019. Contamination and ecological risk of polybrominated diphenyl ethers (PBDEs) in surface sediments of mangrove wetlands: A nationwide study in China. Environ Pollut 249: 992-1001.

Clairmont LK, Stevens KJ, Slawson RM. 2019. Site-specific differences in microbial community structure and function within the rhizosphere and rhizoplane of wetland plants is plant species dependent. Rhizosphere 9: 56-68. 
Demaneche S, Monier JM, Dugat-Bony E, Simonet P. 2011. Exploration of Horizontal Gene Transfer between Transplastomic Tobacco and Plant-Associated Bacteria. FEMS Microbiol Ecol 78: 129-136.

Dighe AS, Jangid K, Gonzalez JM, Pidiyar VJ, Patole MS, Ranade DR, Shouche YS. 2004. Comparison of 16S rRNA Gene Sequences of Genus Methanobrevibacter. BMC Microbiol 4: 20. DOI: :10.1186/1471-2180-4-20.

Garcia MR, Cattani AP, Cunha Lana PD, Rubens Figueira CL, Martins CC. 2019. Petroleum biomarkers as tracers of low-level chronic oil contamination of coastal environments: A systematic approach in a subtropical mangrove. Environ Pollut 249: 1060-1070.

Godini R, Fallahi H. 2019. A brief overview of the concepts, methods and computational tools used in phylogenetic tree construction and gene prediction. Meta Gene 21: 100586

Greenwood D, Barer M, Slack R, Irving W. 2012. Medical Microbiology A Guide to Microbial Infections: Pathogenesis, Immunity, Laboratory Investigation and Control, 18th ed. Elsevier Ltd., New York.

Haichar FZ, Santaella C, Heulin T, Achouak W. 2014. Root exudates mediated interactions belowground. Soil Biol Biochem 77: 69-80.

Heath T, Ogden, Michael S. 2006. Multiple Sequence Alignment Accuracy and Phylogenetic Inference. Syst Biol 55: 314-328.

Heng L. 2006. Constructing The Treefam Database. The Institute of Theoretical Physics Chine Academic of Science, China.

Janda JM, Abbott SL. 2007. 16S rRNA Gene Sequencing for Bacterial Identification in the Diagnostic Laboratory: Pluses, Perils, and Pitfalls. J Clin Microbiol 45(9):2761-2764.

Ji L, Fu X, Wang M, Xu C, Chen G, Song F, Guo S, Zhang Q. 2019. Enzyme cocktail containing NADH regeneration system for efficient bioremediation of oil sludge contamination. Chemosphere 233: 132139.

Khan MAI, Biswas B, Smith E, Naidu R, Megharaj M. 2018. Toxicity assessment of fresh and weathered petroleum hydrocarbons in contaminated soil- a review. Chemosphere 212: 755-767.

Lang E, Griese B, Sproer C, Schumann P, Steffen M, Verbarg. 2007. Characterization of 'Pseudomonas azelaica' DSM 9128, leading to emended descriptions of Pseudomonas citronellolis Seubert 1960 (Approved Lists 1980) and Pseudomonas nitroreducens Iizuka and Komagata 1964 (Approved Lists 1980), including Pseudomonas multiresinivorans as its later heterotypic synonym. Int J Syst Evol Microbiol 57: 878-882

Li K, Chen H, Jiang J, Li X, Xu J, Ma Y. 2016. Diversity of Bacteriome Associated with Phlebotomus chinensis ( Diptera: Psychodidae) Sand Flies in Two Wild Populations from China. Nature 6: 36406.

Madigan MT, Martinko J, Parker J. 2012. Brock Biology of Microorganisms. Benjamin Cummings, San Fransisco.

Meng L, Li W, Bao M, Sun P. 2018. Promoting the treatment of crude oil alkane pollution through the study of enzyme activity. Intl $\mathrm{J}$ Biol Macromol 119: 708-716.

Miller GA, Beckwith R, Fellbaum C, Gross D, Miller K. 1990. Introduction to WordNet: An On-line Lexical Database. Intl J Lexicograph 3: 235-312.

Mishra S, Jyoti J, Kuhad RC, Lal B. 2001. In situ bioremediation potential of an oily sludge-degrading bacterial consortium. Curr Microbiol 43: 328-335.
Mitreva M. 2017. The Microbiome in infectious diseases. In: Infection Diseases, Vol. 1, 4th ed. Elsevier, Dordrecht

Ntougias S, Melidis P, Navrozidou E, Tzegkas F. 2014. Diversity and Efficiency of Anthracene-degrading Bacteria Isolated from a Denitrifying Activated Sludge System Treating Municipal Wastewater. Intl Biodeterior Biodegrad 97: 151-158.

Osborne CA, Galic M, Sangwan P, Janssen PH. 2006. PCR-generated Artefact from 16S rRNA Gene-Specific Primer. FEMS Microbiol Lett 248 (2):183-187.

Ozaki S, Kishimoto N, Fujita T. 2006. Isolation and Phylogenetic Characterization of Microbial Consortia Able to Degrade Aromatic Hydrocarbons at High Rates. Microbes Environ 21: 44-52.

Rajaei S, Seyedi SM, Raiesi F, Shiran B, Raheb J. 2013. Characterization and Potentials of Indigenous Oil-Degrading Bacteria Inhabiting the Rhizosphere of Wild Oat (Avena fatua L.) in South West of Iran. Iran J Biotech 11 (1): 32-40.

Renu, Gupta SK, Rai AK, Sarim KM, Sharma A, Budhlakoti N, Arora D, Verma DK, Singh DP. 2019. Metaproteomic data of maize rhizosphere for deciphering functional diversity. Data in brief: 104574.

Retnaningrum E, Wilopo W. 2018. Production and characterization of biosurfactant produced by Pseudomonas aeruginosa B031 isolated from a hydrocarbon phytoremediation field. Biotropia 25: 130-139.

Sambrook J, Fritsch EF, Maniatis T. 1989. Molecular Cloning, A Laboratory Manual, 2nd Edition. Cold Spring Harbor Laboratory, Cold Spring Harbor, New York.

Santos PM, Roma V, Benndorf D, von Bergen M, Harms H, Sa-Correia I. 2007. Mechanistic insights into the global response to phenol in the phenol-biodegrading strain Pseudomonas sp. M1 revealed by quantitative proteomics. J Integr Biol 11: 233-251.

Sasse J, Martinoia E, Northen T. 2018. Feed your friends: do plant exudates shape the root microbiome? Trends Plant Sci 2(1): 25-41.

Srivastva N, Vishwakarma P, Bhardwaj Y, Singh, A, Manjunath K, Dubey SK. 2017. Kinetic and molecular analyses reveal isoprene degradation potential of Methylobacterium sp. Bioresour Technol 242: 87-91.

Tan GA, Chen C, Ge L, Li L, Tan SN, Wang J. 2015. Bioconversion of Styrene to Poly(hydroxyalkanoate) (PHA) by the new bacterial strain Pseudomonas putida NBUS12. Microbes Environ 30: 76-85.

Van de Peer Y, Lemey P, Salemi M, Vandamme AM. 2009. The Phylogenetic Handbook: A Practical Approach to Phylogenetic Analysis and Hypothesis Testing. Cambridge University Press, London.

Wei X, Zhu Z, Wei L, Wu J, Ge T. 2019. Biogeochemical cycles of key elements in the paddy-rice rhizosphere: Microbial mechanisms and coupling processes. Rhizosphere 10: 100145

Willey J, Sherwood LM, Woolverton CJ. 2008. Prescott, Harley, and Klein's Microbiology Seventh Edition. McGraw-Hill Companies, Inc. New York.

Xu Q, Sun J, Hu Y, Chen J, Li W. 2013. Characterization and Interactions of Anodic Isolates in Microbial Fuel Cells Explored for Simultaneous Electricity Generation and Congo Red Decolorization. Bioresour Technol 142: 101-108. 